Original article

\title{
Prevalence of glaucoma in an eye clinic in Ghana
}

\author{
Kenneth Bentum Otabil, Seth Boateng Tenkorang, Ankrah Lennox Mac, Emmanuel Arkaa Otabil
}

Department of Ocular Research, Emmavick Eye Clinic, Sunyani, Ghana, West Africa

Received 5 May 2013, Accepted 13 June 2013

(C) 2013, Otabil K.B., Tenkorang S.B., Mac A.L., Otabil E.A.

(C) 2013, Russian Open Medical Journal

Abstract: Background - Glaucoma is an important eye disease that causes blindness with a frequency second only to blindness due to cataracts. Early detection of the condition is critical to preventing irreversible blindness in those affected. Objective - The purpose of this study was therefore to determine the prevalence of glaucoma in an eye clinic in Ghana, West Africa and help raise awareness of the situation on the ground. Methods and Results - The study is a retrospective study of the Out-Patient Department morbidity of glaucoma at the Emmavick Eye Clinic in Sunyani, Ghana spanning a period of 35 months. The study included patients visiting the clinic for the first time. The diagnostics tools used included tonometry, ophthalmoscopy (examination of optic disc) and perimetry. Out of a total of 5828 patients seen over the study period, $460(7.89 \%)$ subjects presented with glaucoma. The prevalence of glaucoma in female Adults was $9.52 \%$ whilst that of male adults was $8.77 \%$. The prevalence of glaucoma in children was $1.41 \%$. Conclusion - The result of the present study affirms the fact that glaucoma is more prevalent in the adult population than in the younger population. This situation has a huge toll on the economy of developing countries like Ghana where there is need of much human resource to drive the advance toward highincome status. Mass education and screening is needed to identify affected individuals for early treatment and inform the populace about the insidious nature of glaucoma and its potential to irreversibly impair vision in affected individuals.

Keywords: glaucoma, ophthalmoscopy, perimetry, tonometry, intraocular pressure

Cite as Otabil KB, Tenkorang SB, Mac AL, Otabil EA. Prevalence of glaucoma in an eye clinic in Ghana. Russian Open Medical Journal $2013 ; 2: 0310$.

Correspondence to Kenneth Bentum Otabil. Address: Department of Ocular Research, Emmavick Eye Clinic, P.O Box 918 , Sunyani, Ghana, West Africa. Phone: +233209164671. Email: ekowbentum@yahoo.com

\section{Introduction}

Glaucoma is the second leading cause of blindness, after cataracts $[1,2]$. Worldwide, an estimated 60.5 million people have glaucoma out of which 8.4 million have become blind. The prevalence is estimated to be on the increase and projected to affect 79.6 million people by the year 2020 [3]. The prevalence of glaucoma is about $1 \%$ in the population older than 50 years, and the rate increases with age, being particularly high in Blacks [4]. Africa is disproportionately affected by blindness due to glaucoma. It is documented to blind $1 \%$ of people in Africa. In Nigeria, the disease is reported to blind 147,000 people in the population aged over 40 years [4]. However, Ghana is the most affected country in Africa and second in the world [5], with 8.5 per cent of persons above 40 years having the disease and 7.7 per cent of persons above 30 years also carrying the disease [6]. Being the most frequent cause of irreversible blindness worldwide [7], glaucoma has the second highest DALY score for sense organs second only to cataract [8].

Glaucoma has been nicknamed the "silent thief of sight" because there are usually no symptoms or pain associated with the onset of glaucoma and the loss of vision normally occurs gradually over a long period of time and is often recognized when the disease is quite advanced [9]. The disease is characterized by accelerated loss of optic nerve axons, with either high intraocular pressure (IOP) or normal IOP. It may be accompanied by clinical signs such as progressive cupping of optic nerve and loss of peripheral, then central, vision [10].

Open-angle glaucoma (OAG) is the leading cause of irreversible blindness in Africa. In a study by Quigley and Broman (2006), the prevalence of OAG tend to increase with age from less than $5 \%$ at age 42 to about $20 \%$ for those above age 80 [11]. Other studies have shown that people of African descent have at least $4 \mathrm{X}$ risk of primary open-angle glaucoma (POAG) than non-Africans [7, 12]. A recent study by Adio and Onua (2012) in Nigeria demonstrated that POAG was the most frequent type of glaucoma occurring in the region [13]. Herndon et al (2002) in a clinic-based survey in Ghana also showed that about $70 \%$ of glaucoma in Accra was open angle glaucoma [14].

Although most cases of blindness (75-80\%) can be prevented $[4,15]$ most types of glaucoma cannot be prevented or cured, and once the visual field is lost it can never be regained [16]. Glaucoma causes chronic and progressive damage to the optic nerve and this condition has been shown to lead inexorably to blindness at a rapid rate if treatment is not instituted within months, and up to 3 years in some cases [17-19]. However, in a study from Glasgow [18], it was calculated that if medical treatment was instituted in a timely manner and sustained, the rate of progression of visual field deterioration reduced significantly to $3 \%$ per annum, suggesting it might have taken at least 33 years for glaucomatous eyes to progress to blindness, but most did not present early enough at first onset of the disease, and so blindness appeared to ensue 
rapidly. POAG, which is the most frequent type of glaucoma in Africa, is mostly associated with damage caused by intraocular hypertension can be delayed by medication, surgery, or laser therapy [20] when detected early.

The economic costs associated with visual impairment from glaucoma are considerable [13]. In a recent survey in Nigeria it was demonstrated that the main economic consequences of visual impairment have far reaching impact on the nation as a whole as visual impairment, particularly from glaucoma, has a considerable negative impact on productivity. Visual impairment leads to incapacity and dependence. They conclude that if the health problems caused by glaucoma is eliminated or at least reduced, the quality of life for the people in the country as well as their families could significantly be improved. This could in the end translate into a reduction of the national expenditure by health care services and an increase in productivity.

The importance of early screening and detection in the management and control of glaucoma cannot be overemphasized since the lower mortality rates and higher per capita gross domestic product increase the relative cost-effectiveness of screening and treatment interventions intended to mitigate glaucoma burden [21]. However, even in the developed world fewer than $50 \%$ of those with glaucoma are aware of their disease. In the developing world, the situation is even worse as fewer people are aware of their condition. This has necessitated the need for studies like this to provide evidence to the situation on the ground and create awareness about the disease. This could inform policy making and implementation within the sub-region.

\section{Material and Methods}

\section{Study Site and Period}

This is a retrospective study of the Out-Patient Department morbidity of glaucoma at the Emmavick Eye Clinic in Sunyani, Ghana for a period of 35 months from February, 2010 to December, 2012. The study only included patients visiting the clinic for the first time. Patients coming for review were not included in order to ensure that the same patient is not captured twice. The examination for diagnosis of glaucoma was carried out by an Optometrist and an Ophthalmic Nurse Practitioner.

\section{Study Population}

The total study population was divided into children, Male adults and Female adults. Patients aged 0-15 were grouped as children whilst patients with ages above 15 were categorized either as Male adults or Female adults based on gender. In all, the total study population numbered 5828 out of which 918 were children, 2747 were Male adults and 2163 were Female adults.

\section{Diagnostic Procedure}

The diagnostic procedures used included tonometry, Ophthalmoscopy (examination of optic disc) and Perimetry.

\section{a) Tonometry}

Tonometry was used to measure intraocular pressure (IOP) that sometimes accompanies glaucoma. When used alone however, tonometry may not accurately detect the presence or absence of glaucoma. This is because normal IOP has a diurnal fluctuation of as much as $5 \mathrm{mmHg}$ [22]. Additionally, not everyone with glaucoma has an increased IOP. It is estimated that only half of people with glaucoma have increases in IOP above normal in a random measurement. Tonometry was thus performed alongside other eye examinations in order to diagnose glaucoma accurately. The positive predictive value for diagnosing glaucoma with tonometry has been reported to be $2 \%$ to $5 \%$ [22]. IOP measurements above the upper limit of normal $(21 \mathrm{mmHG})$ have an estimated sensitivity of $47 \%$ and specificity of $92 \%$ for diagnosing POAG. The sensitivity of the classical cut-off for IOP of greater than $21 \mathrm{mmHG}$ is less than $50 \%$. Furthermore, there is no IOP level where a reasonable balance of sensitivity and specificity is obtained [23]. For this study, IOP above $21 \mathrm{mmHG}$ was judged to be abnormal.

\section{b) Ophthalmoscopy-Inspection of the optic disc}

Inspection or visualization of the optic disc (ophthalmoscopy) was carried out by the Optometrist and Ophthalmic Practitioner in order to determine if there is damage to the optic nerve. A dilated eye exam with direct ophthalmoscopy by an optometrist is reported to have an estimated sensitivity of $59 \%$ and specificity of $73 \%$ for detecting glaucoma-associated optic disc changes [24]. Characteristic changes in the structure of the optic nerve were used as diagnostic indicators of glaucoma. However, we must mention again that the ability of these parameters to accurately classify people into disease and non-disease states is relatively poor. Similar to tonometry, there is no cut-point that achieves an adequate sensitivity and specificity balance.

\section{c) Perimetry}

When necessary, patients were referred for perimetry in order to evaluate the visual fields. The integrity of the visual fields determines where a person perceives visual stimuli. It is estimated that up to $30 \%$ to $50 \%$ of the optic nerve fibres must be lost before a classic glaucomatous visual field defect occurs with any consistency. The specificity and sensitivity of perimetry varied depending on the method used as well as the cut-off point for defining visual field defects and the reference standard employed. To establish the presence of visual field defects, several visual field measurements are needed. Measurement of visual fields can be difficult and the reliability of a single measurement may be low. Currently there is no defined standard of progression of visual field defects [25].

\section{Statistical analysis}

Analyses were done using Microsoft Excel 2007 and Graph Pad Prism. Analyses were done using descriptive statistics for frequency distribution and Chi-square analysis. A two-tailed $\mathrm{p}$ value lower than 0.05 was considered statistically significant.

\section{Results}

Data from children, adult males and adult females diagnosed with glaucoma at the study clinic during the study period were analyzed. Figure is a presentation of the number of people with glaucoma from the categories during the study period from 2010 to 2012. It is observed that fewer children consistently presented with glaucoma when compared with adults at the study clinic.

As can be seen from Table, the total number of children presenting with eye cases at the study site for the period was 918 out of a total of 5828 patients who presented at the clinic. Of these 918 presenting with various pathologies, only 13 were 
diagnosed by the optometrist and ophthalmic practitioner as glaucomatous. Thus the prevalence of glaucoma in children presenting at the clinic for the study period was $1.42 \%$.

The total number of adult males as per our categorization, who reported with eye diseases at the study clinic was 2747 out of 5828 who presented at the Out-Patient Department of the study clinic. Of these, only 241 were diagnosed as glaucomatous by our ophthalmic team. The prevalence of glaucomatous males in the study population for the study period was $8.77 \%$.

From Table, it can be seen that there were a total of 2163 female adult patients out of a total number of 5828 patients included in the study. Of these, 206 were clinically diagnosed as having glaucoma. The prevalence of glaucoma in female adults who took part in the study was $9.52 \%$. It is immediately observed that the prevalence of glaucoma is slightly higher in the female adult population $(9.52 \%)$ than that of the male adult population (8.77\%).

It is observed that relatively fewer adult females (206) than adult males (241) presented with glaucomatous eyes although the difference was not statistically significant $(p=0.09)$.

In the general study population, a total of 460 patients who presented at the Out-Patient Department of the eye clinic were clinically diagnosed as glaucomatous (Table). This translates into a prevalence of $7.89 \%$ for glaucoma in the current study.

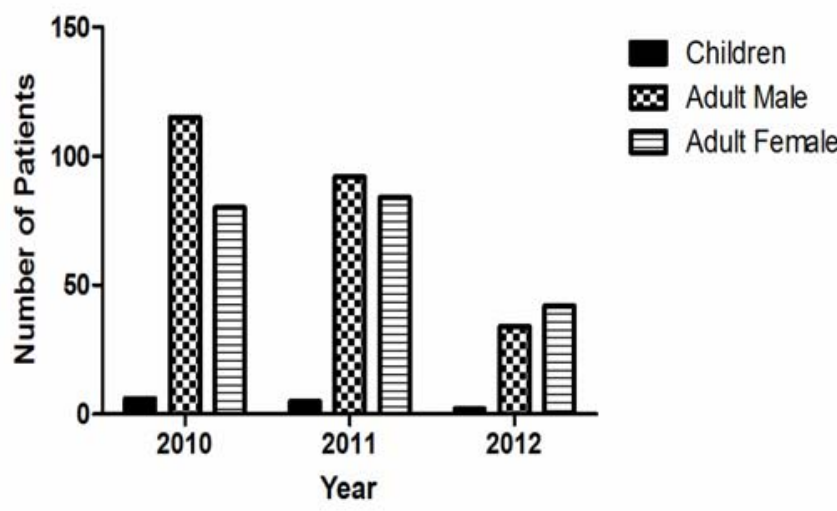

Figure. Distribution of glaucoma among males, females and children.

It can be easily seen that less children presented with glaucoma in relation to adult males and females and the difference was statistically significant $(p=0.03)$. Differences between the number glaucoma cases in males and females was not statistically significant $(p=0.09)$.

Table. Statistics of patients presenting with glaucoma at the study clinic during the study period

\begin{tabular}{lccc}
\hline $\begin{array}{l}\text { Category of } \\
\text { patients }\end{array}$ & $\begin{array}{c}\text { Number of } \\
\text { patients at } \\
\text { clinic }\end{array}$ & $\begin{array}{c}\text { Number of } \\
\text { patients with } \\
\text { glaucoma }\end{array}$ & $\begin{array}{c}\text { Prevalence of } \\
\text { glaucoma in } \\
\text { patients (\%) }\end{array}$ \\
\hline Children & 918 & 13 & 1.42 \\
Adult Male & 2747 & 241 & 8.77 \\
Adult Female & 2163 & 206 & 9.52 \\
Total & 5828 & 460 & 7.89 \\
\hline
\end{tabular}

\section{Discussion}

Glaucoma is the World's leading cause of irreversible blindness, and poses serious public health and economic concerns [26]. It is not only a problem for the diseased person but also for the society especially in developing countries likes ours where social and welfare services are less functional. When detected early, ocular damage due to glaucoma can be halted or at least vision at the time of detection can be maintained through effective medication or surgery. The importance of early detection in preventing irreversible blindness due to glaucoma can therefore not be overemphasized. In spite of the importance of early detection, the level of awareness of glaucoma within the general populace is low. Even more worrying is the fact that less than $50 \%$ of patients with glaucoma are aware they have the disease. It is for this reason that studies like this are needed to determine regional prevalence of glaucoma, help raise awareness and inform policy making.

Ghana is the Sub-Saharan country most afflicted with this insidious eye disease with 8.5 per cent of persons above 40 years having the disease and 7.7 per cent of persons above 30 years also carrying the disease [6]. In this study, the prevalence of glaucoma in the study population was $7.89 \%$. This prevalence is consistent with data of the prevalence of glaucoma in other parts of the country. In a population-based study conducted in 2001 to find the prevalence of blindness in people over 40 years in the Volta region of Ghana, Guzek et al. (2005) found the corrected prevalence for glaucoma in one or both eye was 7.5\% [27].The findings of the present study is however higher than that reported in a Nigerian study by Enock and co-workers where the prevalence was $6.5 \%$ [28].

The prevalence of glaucoma of $7.89 \%$ observed in our study gives cause for concern as the results represent only those whose symptoms are overt and inconveniencing enough to warrant a visit to the clinic. It is expected that these figures will be much higher in the communities as most cases of glaucoma could go unnoticed until peripheral vision is almost completely lost. Again, in the developing world, the culture of voluntary visit to the clinic is not common and most people especially in the rural areas will only visit the clinic when the problem is causing substantial pain or has caused visible damage.

The adult male population had a slightly higher number of patients (241) presenting with the disease than their female counterpart (206). However, the prevalence of glaucoma in the adult female population (9.52\%) was higher than their male counterparts $(8.77 \%)$ even though the difference in prevalence was not statistically relevant $(p=0.0918)$. In the Melbourne and Rotterdam studies, there was a trend towards increased risk for OAG in males; however, this difference did not reach statistical significance, possibly due to small sample sizes $[29,30]$. Also in a study by lqbal et al. (2008) to determine the age and sex distribution as well as types of glaucoma in hospitalized children and adults at Khyber Institute of Ophthalmic Medical Sciences, Hayatabad Medical Complex, Peshawar, glaucoma was more common in males in both groups [31]. Sex appears to be a controversial issue associated with an increased risk of glaucoma. The adult male population has a higher chance of being affected with the disease but generally the female population has a higher prevalence of glaucoma since women have increased longevity compared to men.

The low prevalence of glaucoma in children (1.42\%) was expected since the risk of developing this disease increases with 
age and is more prevalent in adults than in children. Although children may have the developmental glaucomas including primary congenital glaucoma, infantile glaucoma and glaucoma associated with heredity of familial diseases, disease progression is very slow. The pathology of glaucoma is known to have a slow onset with some taking as long as 33 years to develop into absolute glaucoma, the end stage of all un-managed glaucomas, characterized by complete irreversible, blindness. Children also have relatively less exposure to most triggers of glaucoma including trauma, cataracts, drugs etc and are thus less likely to become glaucomatous when compared with adults. The subtle changes in vision due to glaucoma may also be unnoticeable by children unless other symptoms, such as severe pain, are present. Unfortunately, open angle glaucoma which is the most prevalent glaucoma type in Africa progresses painlessly and does not have acute attacks with the only signs being gradually progressive visual field loss and optic nerve damage.

The result of the present study affirms the fact that glaucoma is more prevalent in the adult population than in the younger population. This situation, which indicates that people of productive ages $(<30)$ have a high chance of losing sight due to this disease, has a huge toll on the economy of developing countries like Ghana where there is need of much human resource to drive the advance toward high-income status. Therefore, this disability could result in huge economic loss to developing countries. For this reason, mass education is needed to inform the populace about the insidious nature of glaucoma and its potential to irreversibly impair vision in affected individuals. Furthermore, mass screening is also very necessary to identify individuals living with this eye defect to timely intervene with needed treatment and management procedures since the relative cost-effectiveness of screening and treatment interventions intended to mitigate glaucoma burden is well known [21].

\section{Conclusion}

Our study found that the prevalence of glaucoma in Ghana is consistent with the occurrence of the disease at health care facilities. The study confirms a high incidence of glaucoma in the productive ages of the populace. Consequently, much mass education and screening exercises are needed to remedy the potential loss of human resource to irreversible blindness in the country.

\section{Acknowledgments}

We do aknowledge the efforts of all staff of Emmavick Eye Clinic who contributed in various capacities towards the research work.

\section{Conflict of interest: none declared}

\section{References}

1. Kingman S. Glaucoma is second leading cause of blindness globally. Bull World Health Organ 2004; 82(11): 811-890. (PMCID: PMC2623060)

2. Nduaguba C, Lee R. Glaucoma screening: current trends, economic issues, technology, and challenges. Curr Opin Ophthal-mol 2006; 17 : 142-152. (doi: 10.1097/01.icu.0000193088.75432.c9) (PMID: 16552249)

3. Gupta N, Yülel YH. Glaucoma as a neurodegenerative disease. Curr Opin Ophthalmol 2007, 18: 110-114. (PMID: 10416754) (doi: 10.1097/ICU.0b013e3280895aea)
4. Kyari F, Gudlavaletti MV, Sivsubramaniam S, Gilbert CE, Abdull MM, Entekume G, et al. Prevalence of blindness and visual impairment in Nigeria. Invest Ophthalmol Vis Sci 2009; 50: 2033-2039. (doi: 10.1167/iovs.08-3133) (PMID: 19387071)

5. Melamed C, Herndon L, Shaarawy T. The 1st African Glaucoma Summit Vol. 2010. August 6-7, 2010, Accra, Ghana. URL: http://www.worldglaucoma.org/ AfricaSummit/ index.php

6. Ghana News Agency (2008). Ghana, a leader in glaucoma cases - GHS URL: http://www.ghanaweb.com/GhanaHomePage/NewsArchive/ artikel.php?ID=151371

7. Resnikoff S, Pascolini D, Etya'ale D, Kocur I, Pararajasegaram R, Pokharel GP, Mariotti SP. Global data on visual impairment in the year 2002. Bulletin World Health Org 2004; 82: 844-851. (PMID: 15640920) (PMCID: PMC2623053)

8. WHO (2000). World Health Report 2000. Annex Table 4. URL: http://www.who.int/whr2001/ 2001/ archives/2000/en/pdf/ StatisticalAnnex.pdf.

9. Harvard Health News (2010). Treating glaucoma, the "thief of sight," from Harvard's Aging Eye Special Health Report. URL: http://www.health.harvard.edu/press_releases/treating-glaucomathe-thief-of-sight.

10. A.D.A.M. Medical Encyclopedia (2013). Glaucoma. URL: http://www.ncbi.nlm.nih.gov/pubmedhealth/ PMH0002587/

11. Quigley HA, Broman AT. The number of people with glaucoma worldwide in 2010 and 2020. Br J Ophthalmol 2006; 90: 262-267. (PMID: 16488940) (PMCID: PMC1856963)

12. Sommer A, Tielsch JM, Katz J, Quigley HA, Gottsch JD, Javitt J, Singh K. Relationship between intraocular pressure and primary open angle glaucoma among white and black Americans. The Baltimore Eye Survey. Arch Ophthalmol 1991; 109: 1990-1995. (PMID: 1867550) (doi: 10.1001/archopht.1991.01080080050026)

13. Adio AO, Onua AA. Economic burden of glaucoma in Rivers State, Nigeria. Clin Ophthalmol 2012; 6: 2023-2031. (doi: 10.2147/OPTH.S37145) (PMID: 23271881)

14. Herndon LW, Challa P, Ababio-Danso B, Boateng JO, Broomer B, Ridenhour $\mathrm{P}$, Allingham RR. Survey of glaucoma in an eye clinic in Ghana, West Africa. J Glaucoma 2002; 11(5): 421-425. (PMID: 12362082)

15. Klauss V, Schaller UC. Tropical ophthalmology - prevention and therapy. Ophthalmologe 2004; 101: 741-763. (PMID: 15205906) (doi: 10.1007/s00347-004-1039-8)

16. The Glaucoma Foundation (2013). Frequently asked questions. URL: http://www.glaucomafoundation.org /info_new.php?id=156\&cat=12. Accessed on 06/03/2013

17. Foster A, Resnikoff S. The impact of Vision 2020 on global blindness. Eye 2005; 19: 1133-1135. (doi: 10.1038/sj.eye.6701973) (PMID: 16304595)

18. Smith RJ. The Lang lecture 1986. The enigma of primary open angle glaucoma. Trans Ophthalmol Soc UK 1986; 105: 618-633. (PMID: 3310339)

19. Wormald R, Wilkins MR, Bunce C. Post-operative 5-fluorouracil for glaucoma surgery. Cochrane Database Syst Rev 2000; 2: CD001132. (PMID: 11686977) (doi: 10.1002/14651858.CD001132)

20. Omoti AE. A review of the choice of treatment in primary open angle glaucoma. Niger J Clin Pract 2005; 8: 29-34.

21. Wittenborn JS, Rein DB. Cost-effectiveness of glaucoma interventions in Barbados and Ghana. Optom Vis Sci 2011; 88(1): 155-163. (doi: 10.1097/OPX. 0b013e3181fc30f3) (PMID: 21076360)

22. Canadian Task Force (1995). Periodic health examination, 1996 update: screening for visual problems among elderly patients. Can Med Assoc J 1995; 152(8): 1211-1222.

23. Tielsch JM. The epidemiology and control of open angle glaucoma: a population-based perspective. Annu Rev Public Health 1996; 17: 121136. (PMID: 8724220) 
24. Fleming D, Whitlock EP, Beil T, Smit B, Harris RP. Screening for primary open-angle glaucoma in the primary care setting: an update for the U.S. preventative services task force. URL: http://www.ahrq.gov/clinic/uspstf05/glaucoma/glaucup.htm

25. United States Preventative Task Force (2005). Screening for glaucoma: recommendation statement. Ann Fam Med 2005; 3(2): 171-172. (doi: 10.1370/afm.294) (PMCID: PMC1466863)

26. Dirani M, Crowston JG, Taylor PS, Moore PT, Rogers S, Pezzullo ML, Keeffe JE, Taylor HR. Economic impact of primary open-angle glaucoma in Australia. Clin Experiment Ophthalmol 2011; 39(7): 623632. (doi: 10.1111/j.1442-9071.2011.02530.x) (PMID: 21631669)

27. Guzek JP, Anyomi FK, Fiadoyor S, Nyonator F. Prevalence of blindness in people over 40 years in the Volta region of Ghana. Ghana Medical Journal 2005; 39(2): 55-62. (PMID: 17299544) (PMCID: PMC1790811)

28. Enock ME, Omoti $A E$, Momoh RO. Glaucoma in a suburban tertiary care hospital in Nigeria. J Ophthalmic Vis Res 2010; 5: 87-91. (PMCID: PMC3380680)

29. de Voogd S, Ikram MK, Wolfs RC, Jansonius NM, Hofman A, de Jong PT. Incidence of open-angle glaucoma in a general elderly population: the Rotterdam Study. Ophthalmology 2005; 112: 1487-1493. (PMID: 16039716) (doi: 10.1016/j.ophtha.2005.04.018)

30. Mukesh BN, McCarty CA, Rait JL, Taylor HR. Five year incidence of open-angle glaucoma: the visual impairment project. Ophthalmology 2002; 109(6): 1047-1051. (PMID: 12045042)

31. Iqbal S, Khan Z, Shah SA, Khan MY. Types and presentation of glaucoma. JPMI 2008; 22(4): 324-332.

Authors:

Kenneth Bentum Otabil - BSc., Mphil., Head of Department of Ocular Research, Emmavick Eye Clinic, Sunyani, Ghana, West Africa;

Seth Boateng Tenkorang - BSc., MSc., Department of Ocular Research, Emmavick Eye Clinic, Sunyani, Ghana, West Africa;

Ankrah Lennox Marc - BSc., MSc., Department of Ocular Research, Emmavick Eye Clinic, Sunyani, Ghana, West Africa;

Emmanuel Arkaa Otabil - SRN, Head of Consulting, Emmavick Eye Clinic, Sunyani, Ghana, West Africa. 